\title{
Outcome of patients with glioblastoma in Saudi Arabia: Single center experience
}

\author{
ABDULLAH K. ALTWAIRGI ${ }^{1}$, WALEED ALGAREEB ${ }^{1}$, GAAEM YAHYA $^{1}$, AHMED M. MAKLAD $^{2,3}$, \\ MOAMEN MOM ALY ${ }^{2,4}$, WAFA AL SHAKWEER ${ }^{5}$, ALI BALBAID ${ }^{2}$, EYAD ALSAEED $^{2}$, \\ HUSSAIN ALHUSSAIN $^{2}$, YASSIR ORZ ${ }^{6}$, AHMED LARY ${ }^{6}$ and ASHRAF ELYAMANY ${ }^{1}$ \\ ${ }^{1}$ Medical Oncology Department; ${ }^{2}$ Radiation Oncology Department, Comprehensive Cancer Center, King Fahad Medical City, \\ Riyadh 11525, Saudi Arabia; ${ }^{3}$ Clinical Oncology and Nuclear Medicine Department, Sohag University, Sohag 11432 ; \\ ${ }^{4}$ Radiotherapy and Nuclear Medicine Department, South Egypt Cancer Institute, Assiut University, Assiut 71515, Egypt; \\ ${ }^{5}$ Pathology and Clinical Laboratory Medicine Department; ${ }^{6}$ National Neuroscience Institute, \\ King Fahad Medical City, Riyadh 11525, Saudi Arabia
}

Received November 30, 2015; Accepted February 25, 2016

DOI: $10.3892 / \mathrm{mco} .2016 .818$

\begin{abstract}
Glioblastoma multiforme (GBM), the most common primary brain tumor in adults, is associated with one of the worst 5 year survival rates among all human cancer types. To date, no published data are available for the outcome of this disease in Saudi Arabia. The present study performed a single-center, retrospective cohort study to evaluate the outcome of patients with GBM in Saudi Arabia. The Comprehensive Cancer Center at King Fahad Medical city (Riyadh, Saudi Arabia) was used in the present study. All adult patients ( $\geq 18$ years) diagnosed with histologically proven GBM between January 2008 and December 2013 were included in the present study. A total of 90 patients were treated during the specified period. Of this, $73(81 \%)$ patients underwent resection and 17 (19\%) had biopsy only. The majority of patients $(\mathrm{n}=88 ; 98 \%)$ received radiotherapy (XRT): $67(76 \%)$ with standard and 21 (24\%) with hypo-fractionated dosage. Of the total patients, $65(72 \%)$ received combined modality therapy [standard XRT concurrently with Temozolmide (TMZ)]. The 6 month progression-free survival rate was $43 \%$ for all patients and $55 \%$ for the combined modality subgroup. The median overall survival (OS) for all patients was 13.7 months. However, the median OS for patients treated with combined modality was 19.7 months. In this single-center retrospective study, the outcomes of patients with GBM were similar to
\end{abstract}

Correspondence to: Dr Abdullah K. Altwairgi, Medical Oncology Department, Comprehensive Cancer Centre, King Fahad Medical City, P.O. Box 59046, Dabab Street, Sulemania, Riyadh 11525, Saudi Arabia

E-mail: aaltwairqi@kfmc.med.sa

Key words: glioblastoma multiforme, brain tumor, temozolmide, median overall survival, radiotherapy those in previously reported studies. An improved outcome was associated with an improved performance status, absence of residual disease and use of adjuvant TMZ.

\section{Introduction}

Malignant primary brain tumors are a fairly uncommon malignancy, representing 2-3\% of all adult tumors in Saudi Arabia. Glioblastoma multiforme (GBM) is the most common and most malignant primary tumor of the brain. It arises from astrocytes, and is characterized by rapid growth and short time to progression. Consequently, it is associated with one of the worst 5 year survival rates amongst all human cancer types (1-4).

The standard of care in patients with GBM includes maximal surgical resection, followed by radiotherapy (60 Gy in 30 fractions) with concomitant and adjuvant temozolomide (TMZ). The addition of TMZ to radiation therapy has increased both the median survival (12.1 to 14.6 months) and the 2 year survival duration (10 to 26\%) (5). Despite recent advances in the understanding of the molecular mechanism of tumorigenesis, the outcome of patients with cancer remains poor and therefore there is an urgent requirement for more effective initial treatments for this intractable disease (6-10). Recent therapies under investigation include immunotherapy, chemotherapy, targeted molecular therapy, antiangiogenic therapy, gene therapy, radiation-enhancement and drugs for overcoming resistance (11).

Although prognosis is extremely poor, a limited number of patients with GBM do survive past 36 months. However, a limited understanding of the predictors for survival amongst patients with GBM exists. Additionally, no studies have as yet examined the outcome of GBM in Saudi Arabia. Therefore the aim of the present study was to assess the real world outcome of patients with GBM in this region and to determine the important clinical, pathological and molecular prognostic factors correlated with patient outcomes in this population. 


\section{Patients and methods}

Study design. The present single-center retrospective cohort study was performed in the Comprehensive Cancer Center at King Fahad Medical city (Riyadh, Saudi Arabia). The present study was approved by the local Ethics Committee of the Comprehensive Cancer Center (no. 14-163).

Patients. All adult patients (>18-years-old), who were diagnosed with histologically proven GBM between January 2008 and December 2013 were included in the present study.

Intervention. Patients underwent either a biopsy or a resection, following which they received standard or hypo-fractionated radiotherapy (XRT), with or without concurrent temozolmide (TMZ), as the current standard of care. Following completion of XRT, a proportion of patients received further cycles of TMZ.

Data collection. The data were obtained from electronic medical records, where a data collection form was developed to collect patient demographics, pathology, XRT and chemotherapy details, and progression and survival outcomes. The patient and tumor characteristics are categorized, as shown in Tables I and II.

Statistical analysis. The OS and progression-free survival (PFS) were estimated using Kaplan-Meier methodology. Univariate analyses were performed using the log-rank test and multivariate analyses using the Cox proportional hazards model. $\mathrm{P}<0.05$ was considered to indicate a statistically significant difference. All analyses were performed using SPSS version 22 (IBM SPSS, Armonk, NY, USA).

\section{Results}

A total of 129 patients with newly diagnosed GBM were identified for inclusion in the present study (Fig. 1). Of these patients, 39 had missing data and were excluded from the analysis. Therefore, the data from 90 patients was included for analysis in the final study population: 67 (74.4\%) males and $23(25.6 \%)$ females, with a median age of 49.0 (Table I).

Tumor characteristics were described in Table II. The majority of patients $(87 \%)$ were diagnosed with a GBM, whilst the remaining $13 \%$ were diagnosed with GBM variants, most commonly oligodendroglioma $(n=7 / 12,58 \%)$. Frontal $(24 \%)$ and temporal $(23 \%)$ tumors were the most common tumor sites, with almost half of the tumors (49\%) located in the right hemisphere. In general, the methylation status of the tumor could not be determined.

In the study cohort, $81 \%$ of patients underwent resection, whilst the remaining $19 \%$ underwent biopsy only (Fig. 2). Of those patients who had their tumors resected, the majority $(81 \%)$ were deemed to have residual disease following surgery. The majority (98\%) of patients received XRT; most received standard XRT $(n=67 / 88,76 \%)$ whilst the remaining $24 \%$ received a hypo-fractionated dosage (Fig. 2). The median dose of radiotherapy was $59.4 \mathrm{~Gy}$. Concurrent TMZ was received by $72 \%$ of patients. Notably, whilst nearly all patients $(n=65 / 67$, 97\%) receiving standard XRT also received TMZ, only a
Table I. Patient characteristics $(n=90)$.

\begin{tabular}{lc}
\hline $\begin{array}{l}\text { Characteristic } \\
\text { No. patients, } \\
\text { n }(\%)\end{array}$ \\
\hline $\begin{array}{l}\text { Age, years (range) } \\
\text { Median }\end{array}$ \\
$\begin{array}{l}\text { G5 } \\
\text { Gender }\end{array}$ \\
Male & $49(18-81)$ \\
Female & \\
Eastern Cooperative Oncology Group & $67(74)$ \\
$\leq 2$ & $23(26)$ \\
$>2$ & \\
Co-morbidities & $54(60)$ \\
Yes & $36(40)$ \\
No & \\
Year of diagnosis & $36(40)$ \\
2008 & $54(60)$ \\
2009 & \\
2010 & \\
2011 & $14(15)$ \\
2012 & $17(19)$ \\
2013 & $10(11)$ \\
\hline
\end{tabular}

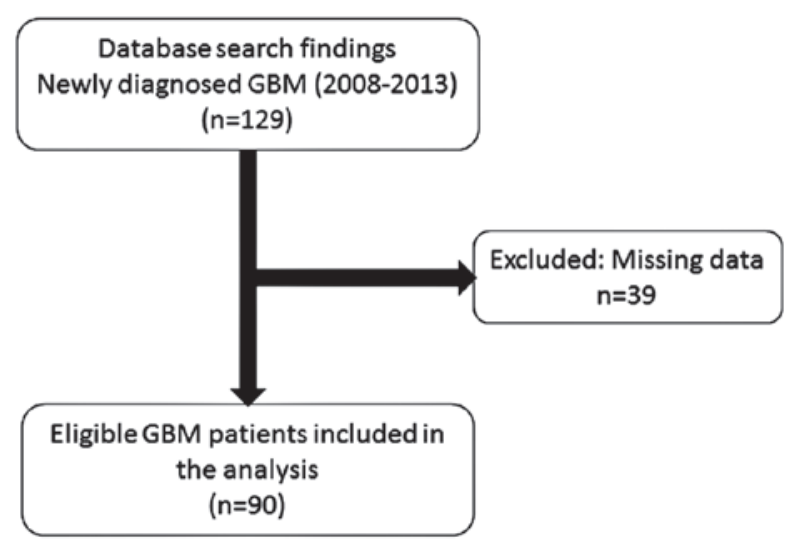

Figure 1. Description of study cohort.

quarter $(n=5 / 21,24 \%)$ of those receiving hypo-fractionated dose also received TMZ. Following completion of XRT, the majority of patients $(n=55 / 90,61 \%)$ received further cycles of TMZ, although half were unable to complete their chemotherapy regimen.

The median PFS was 5.3 months [95\% confidence intervals (CI), 4.47-6.62], with 43\% PFS at 6 months (Fig. 3A). The median OS was 13.7 months (95\% CI, 10.1-17.5), with 53\% OS at 1 year and median follow-up 12.5 months (1.5-70.2 months; Fig. 3B). The PFS and OS were also examined in the subset of patients who received standard XRT with concurrent TMZ $(\mathrm{n}=65)$. In these patients, the median PFS was 6.7 months (95\% CI, 4.7-11), with a 6 month PFS of 55\% (Fig. 4A). The median OS was 19.7 months $(95 \%$ CI, 11.9-27.4), with a 1 year OS of $65 \%$ (Fig. 4B). 


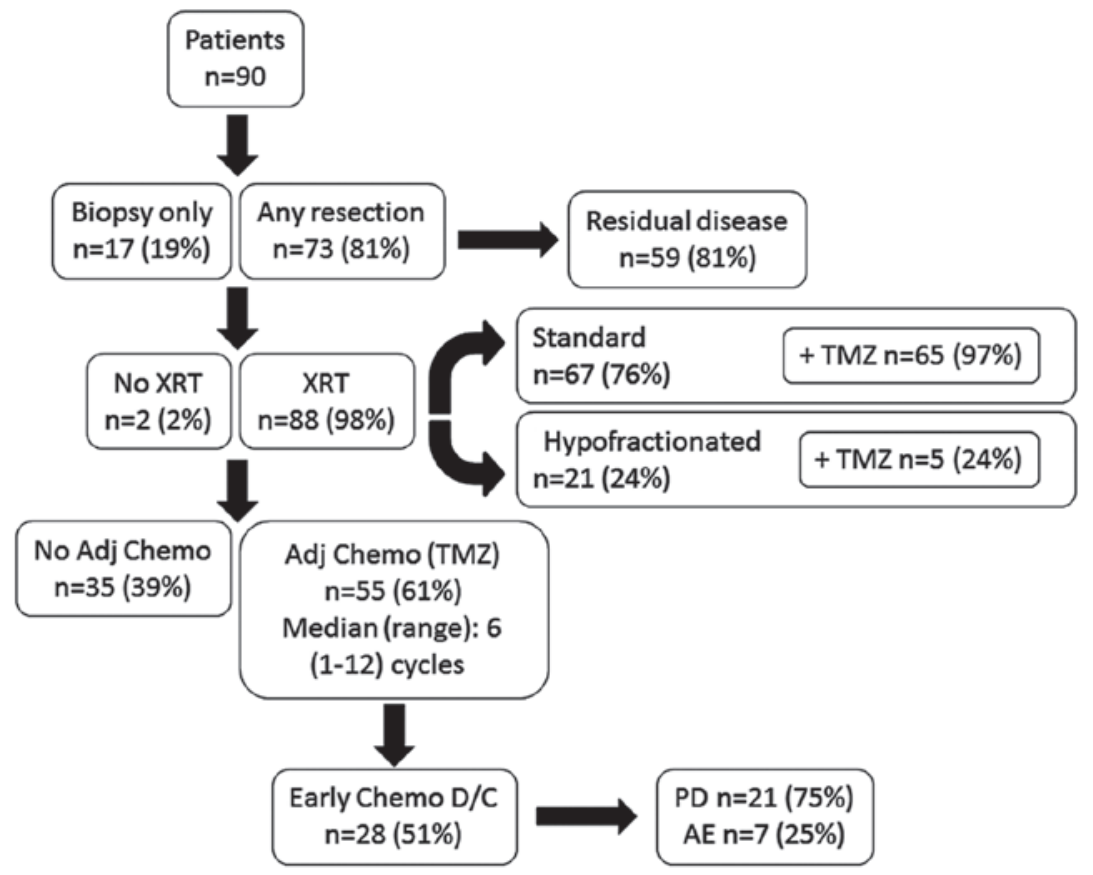

Figure 2. Treatment exposure of patients.

Table II. Tumor characteristics $(\mathrm{n}=90)$.

\begin{tabular}{lc}
\hline Characteristic & No. patients, \\
$\mathrm{n}(\%)$
\end{tabular}

GBM, glioblastoma multiforme; MGMT, $\mathrm{O}^{6}$-methylguanin-DNA-methyltransferase

To determine the factors, which may be associated with PFS and OS, univariate and multivariate analyses were performed. In univariate analysis, age, Eastern Cooperative
Oncology Group (ECOG) performance scale, surgery type, presence of residual disease, type of radiotherapy and receipt of chemotherapy were all predictors of both PFS and OS (Tables III and IV). However, in multivariate analysis, only ECOG $\leq 2$ [odds ratio (OR), 0.3; $\mathrm{P}<0.001$ ], absence of residual disease $(\mathrm{OR}, 0.3 ; \mathrm{P}=0.02)$ and receipt of adjuvant $\mathrm{TMZ}$ $(\mathrm{OR}, 0.5 ; \mathrm{P}=0.05)$ were significant predictors of survival (Tables III and IV).

\section{Discussion}

The present retrospective analysis is the first study, to the best of our knowledge, to examine the outcome of patients with malignant GBM in Saudi Arabia, and to determine the important clinical and pathological prognostic factors that are correlated with the outcome in this region.

A median PFS of 5.3 months and a median OS of 13.7 months was demonstrated. These results are consistent with previous studies in patients with GBM $(5,12,13)$. A 6 month PFS of $43 \%$ and a 1 year OS of $53 \%$ was observed, which was also in line with previous studies. Notably, the PFS and OS were improved in the subgroup analysis of patients receiving combined modality treatment, reflecting recent studies which demonstrated that addition of concomitant chemotherapy to XRT resulted in improved outcomes $(14,15)$.

In the present multivariate analysis, only ECOG, residual disease and receipt of chemotherapy were significant predictors of survival. Previous studies have reported that age, tumor grade (anaplastic glioma vs. GBM), Karnofsky performance status, the number of molecular alterations and the extent of initial surgical resection are all prognostic factors for outcome in patients with GBM. Therefore in general, the present results are in line with those reported elsewhere. Although no randomized controlled trials have been performed to 
Table III. Univariate and multivariate analysis for progression-free survival.

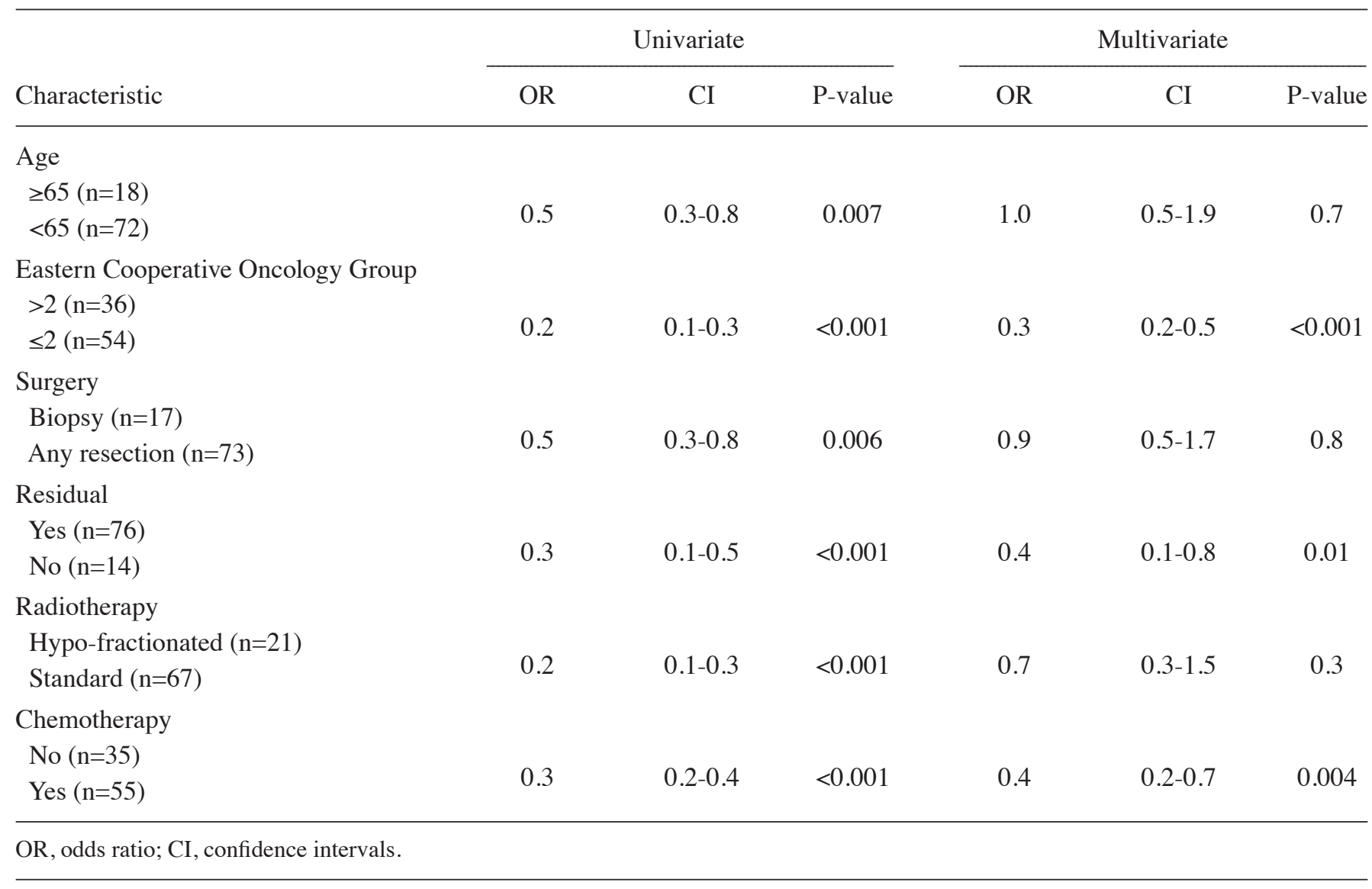

Table IV. Univariate and multivariate analysis for overall survival.

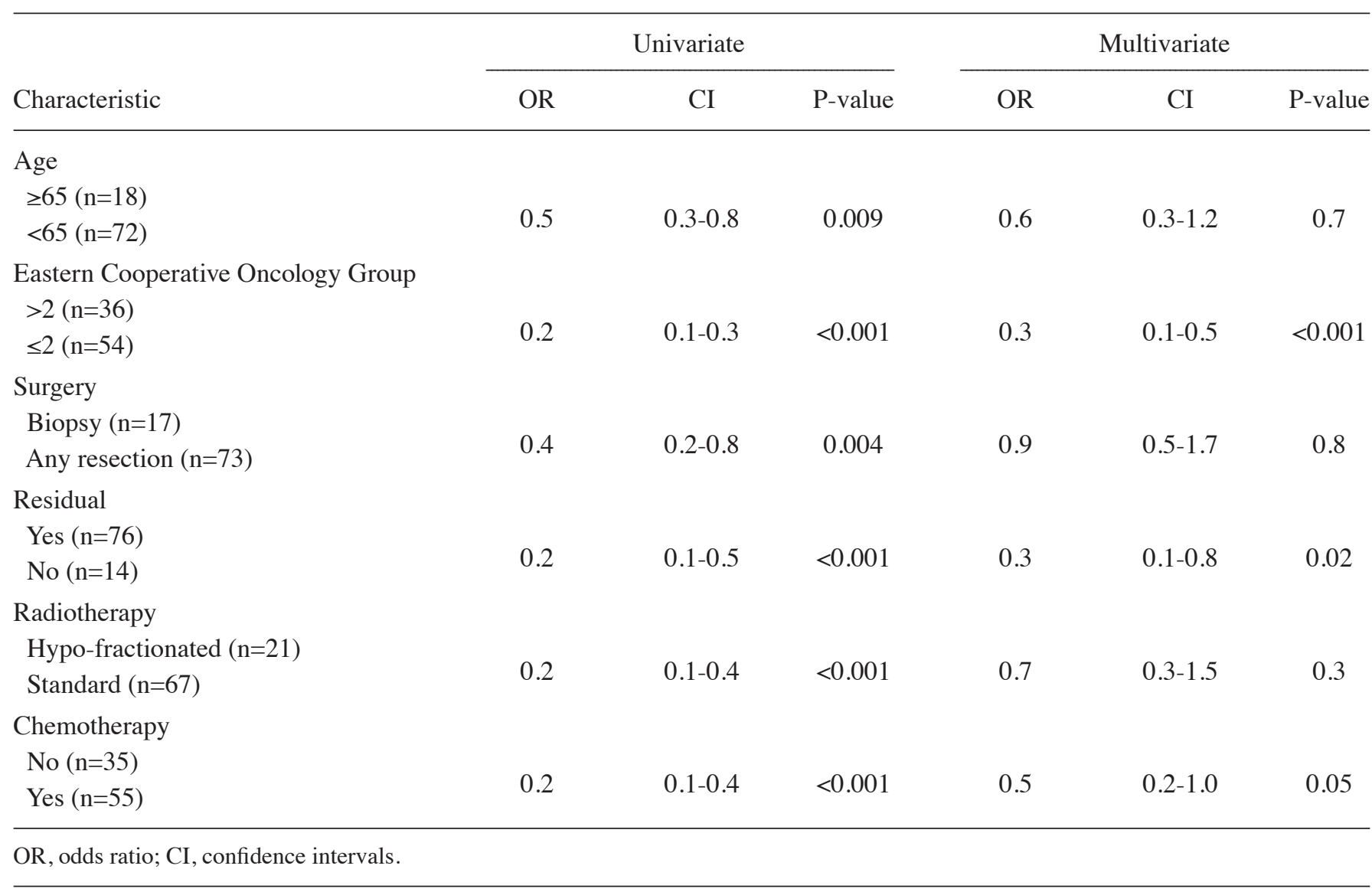


A

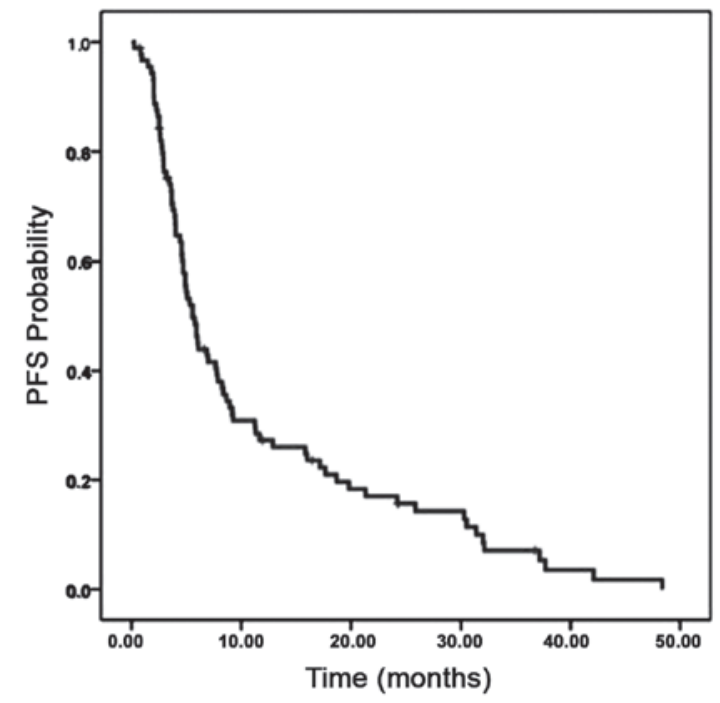

B

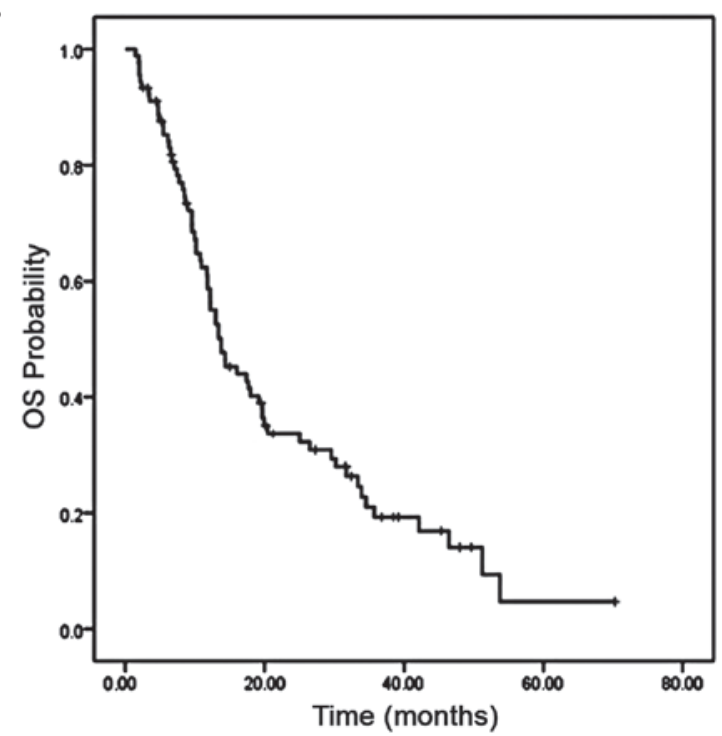

Figure 3. (A) PFS and (B) OS for all patients (n=90). PFS, Progression-free survival; OS, overall survival.

establish the benefit of maximal surgical resection over a more limited resection, numerous previous studies have suggested that maximal resection, particularly gross total resection, does improve survival (16-24). However, evidence remains conflicting, with further studies failing to show a benefit with more extensive surgical resection (either subtotal resection vs. biopsy, or complete vs. subtotal resection) (25-27). The association of chemotherapy with survival is supportive of recent trials demonstrating superior outcomes for those patients treated with combined modality therapy compared with radiotherapy alone (5). Age was not predictive of XRT, which is in contrast to previous studies reporting that age is a reliable predictor for outcome and treatment response in elderly patients with glioma (28-31). Another previous study revealed that age was only prognostic in patients undergoing biopsy, however, not in those undergoing resection (32). As a result of the small number of biopsy patients within the present study, age was not determined as a prognostic for biopsy patients within the present population.
A

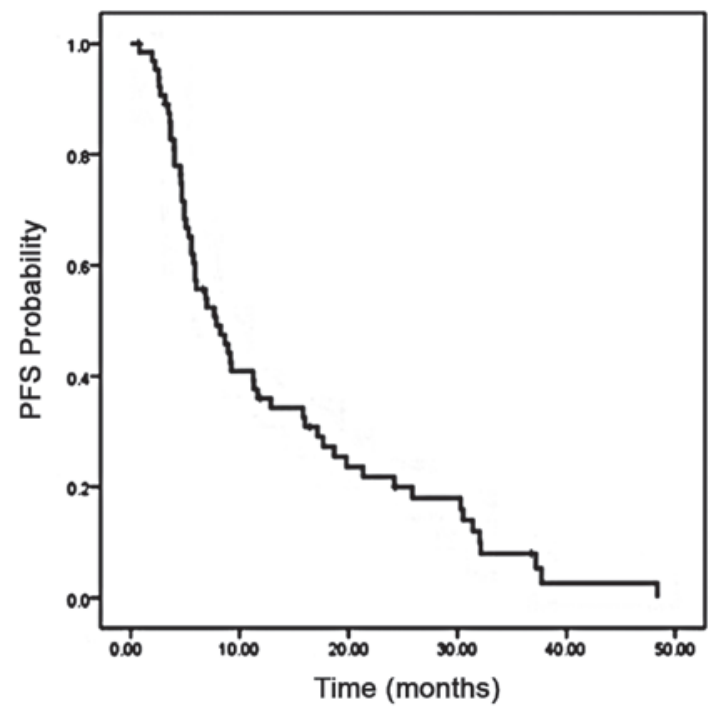

B

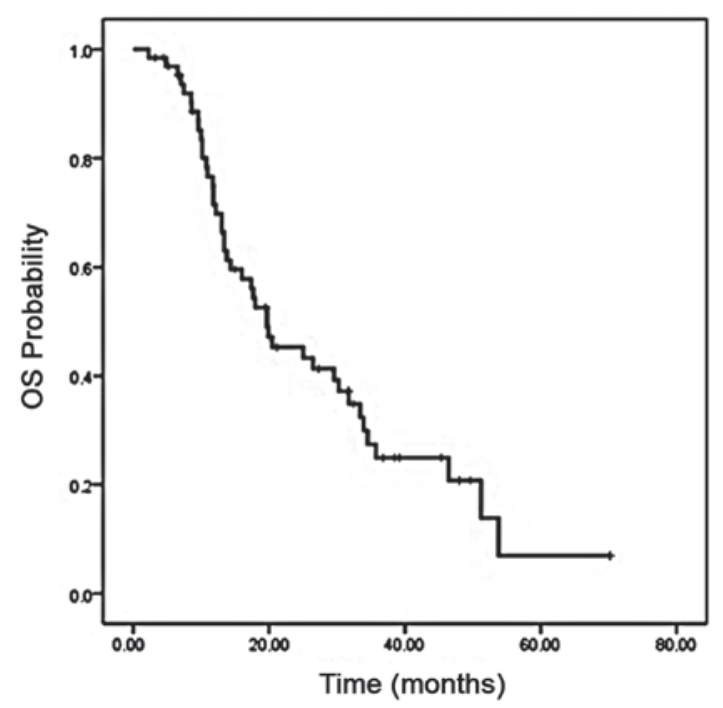

Figure 4. (A) PFS and (B) OS probability over time for patients who received combined modality treatment $(n=65)$. PFS, Progression-free survival; OS, overall survival.

Certain limitations to the present study exist. Due to the retrospective nature of the present study, certain data was missing and therefore a third of the original population were excluded from the analysis due to this. Although the present study attempted to control for potential confounders through multivariate analyses, a randomized controlled trial may provide a more robust environment to control for factors which may influence the outcome. Additionally, other factors which could not be collected, including tumor size and extent of resection, may have impacted on patient outcome. Another limitation was that treatment conditions for patients in the present study were heterogeneous since administration of adjuvant chemotherapy was based on personal preferences and experience. In addition, since the present study was a single centre study, it is possible that results are not fully generalizable across Saudi Arabia. Furthermore, evaluation of pseudo-progression may not have been systematic as the common response criteria were unclear. Molecular profiling data for $\mathrm{O}^{6}$-methylguanin-DNA-methyltransferase-status was not part of routine assessment during the majority of the study time-frame and is therefore not complete for the majority 
of patients. Previous studies have suggested that symptom type and histological factors, including necrosis, endothelial abnormalities and degree of anaplasia are important prognostic factors and these were not included in the present analysis (33-35).

In conclusion, the present study found that outcomes for patients in Saudi Arabia with GBM are in line with those reported in previous studies worldwide. Good performance status at diagnosis, absence of residual disease and chemotherapy were independently associated with an improved outcome. Future studies must examine these factors further, whilst clinicians must focus on optimizing these components within their treatment of patients with GBM, in order to improve outcomes.

\section{References}

1. Ohgaki H, Dessen P, Jourde B, Horstmann S, Nishikawa T, Di Patre PL, Burkhard C, Schüler D, Probst-Hensch NM, Maiorka PC, et al: Genetic pathways to glioblastoma: A population-based study. Cancer Res 64: 6892-6899, 2004.

2. Ohgaki H and Kleihues P: Population-based studies on incidence, survival rates and genetic alterations in astrocytic and oligodendroglial gliomas. J Neuropathol Exp Neurol 64: 479-489, 2005.

3. Bauchet L, Mathieu-Daudé H,Fabbro-Peray P, Rigau V,Fabbro M, Chinot O, Pallusseau L, Carnin C, Lainé K, Schlama A, et al: Oncological patterns of care and outcome for 952 patients with newly diagnosed glioblastoma in 2004. Neuro Oncol 12: 725-735, 2010.

4. Stewart LA: Chemotherapy in adult high-grade glioma: A systematic review and meta-analysis of individual patient data from 12 randomised trials. Lancet 359: 1011-1018, 2002.

5. Stupp R, Mason WP, van den Bent MJ, Weller M, Fisher B, Taphoorn MJ, Belanger $\mathrm{K}$, Brandes AA, Marosi C, Bogdahn U, et al: Radiotherapy plus concomitant and adjuvant temozolomide for glioblastoma. N Engl J Med 352: 987-996, 2005.

6. Bokstein F, Shpigel S and Blumenthal DT: Treatment with bevacizumab and irinotecan for recurrent high-grade glial tumors. Cancer 112: 2267-2273, 2008.

7. Friedman HS, Prados MD, Wen PY, Mikkelsen T, Schiff D, Abrey LE, Yung WK, Paleologos N, Nicholas MK, Jensen R, et al: Bevacizumab alone and in combination with irinotecan in recurrent glioblastoma. J Clin Oncol 27: 4733-4740, 2009.

8. Kreisl TN, Kim L, Moore K, Duic P, Royce C, Stroud I, Garren N, Mackey M, Butman JA, Camphausen K, et al: Phase II trial of single-agent bevacizumab followed by bevacizumab plus irinotecan at tumor progression in recurrent glioblastoma. J Clin Oncol 27: 740-745, 2009.

9. Reardon DA and Wen PY: Therapeutic advances in the treatment of glioblastoma: Rationale and potential role of targeted agents. Oncologist 11: 152-164, 2006.

10. Vredenburgh JJ, Desjardins A, Herndon JE II, Marcello J, Reardon DA, Quinn JA, Rich JN, Sathornsumetee S, Gururangan S, Sampson J, et al: Bevacizumab plus irinotecan in recurrent glioblastoma multiforme. J Clin Oncol 25: 4722-4729, 2007.

11. Kanu OO, Mehta A, Di C, Lin N, Bortoff K, Bigner DD, Yan H and Adamson DC: Glioblastoma multiforme: A review of therapeutic targets. Expert Opin Ther Targets 13: 701-718, 2009.

12. Smrdel U, Kovac V, Popovic M and Zwitter M: Glioblastoma patients in Slovenia from 1997 to 2008. Radiol Oncol 48: 72-79, 2014.

13. Rosenthal MA, Drummond KJ, Dally M, Murphy M, Cher L, Ashley D, Thursfield V and Giles GG: Management of glioma in Victoria (1998-2000): Retrospective cohort study. Med J Aust 184: 270-273, 2006.

14. Gutenberg A, Bock HC, Reifenberger G, Brück W and Giese A: Toxicity and survival in primary glioblastoma patients treated with concomitant plus adjuvant temozolomide versus adjuvant temozolomide: Results of a single-institution, retrospective, matched-pair analysis. Acta Neurochir (Wien) 155: 429-435, 2013.

15. Stummer W, Meinel T, Ewelt C, Martus P, Jakobs O, Felsberg J and Reifenberger G: Prospective cohort study of radiotherapy with concomitant and adjuvant temozolomide chemotherapy for glioblastoma patients with no or minimal residual enhancing tumor load after surgery. J Neurooncol 108: 89-97, 2012.
16. Bucci MK, Maity A, Janss AJ, Belasco JB, Fisher MJ, Tochner ZA, Rorke L, Sutton LN, Phillips PC and Shu HK: Near complete surgical resection predicts a favorable outcome in pediatric patients with nonbrainstem, malignant gliomas: Results from a single center in the magnetic resonance imaging era. Cancer 101: 817-824, 2004.

17. Devaux BC, O'Fallon JR and Kelly PJ: Resection, biopsy and survival in malignant glial neoplasms. A retrospective study of clinical parameters, therapy and outcome. J Neurosurg 78: 767-775, 1993.

18. Kreth FW, Thon N, Simon M, Westphal M, Schackert G, Nikkhah G, Hentschel B, Reifenberger G, Pietsch T, Weller M, et al: Gross total but not incomplete resection of glioblastoma prolongs survival in the era of radiochemotherapy. Ann Oncol 24: 3117-3123, 2013.

19. Lacroix M, Abi-Said D, Fourney DR, Gokaslan ZL, Shi W, DeMonte F, Lang FF, McCutcheon IE, Hassenbusch SJ, Holland E, et al: A multivariate analysis of 416 patients with glioblastoma multiforme: Prognosis, extent of resection and survival. J Neurosurg 95: 190-198, 2001.

20. Laws ER, Parney IF, Huang W, Anderson F, Morris AM, Asher A, Lillehei KO, Bernstein M, Brem H, Sloan A, et al: Survival following surgery and prognostic factors for recently diagnosed malignant glioma: Data from the glioma outcomes project. J Neurosurg 99: 467-473, 2003.

21. Pichlmeier U, Bink A, Schackert G and Stummer W; ALA Glioma Study Group: Resection and survival in glioblastoma multiforme: An RTOG recursive partitioning analysis of ALA study patients. Neuro Oncol 10: 1025-1034, 2008.

22. Simpson JR, Horton J, Scott C, Curran WJ, Rubin P, Fischbach J, Isaacson S, Rotman M, Asbell SO and Nelson JS: Influence of location and extent of surgical resection on survival of patients with glioblastoma multiforme: Results of three consecutive radiation therapy oncology group (RTOG) clinical trials. Int J Radiat Oncol Biol Phys 26: 239-244, 1993

23. Stummer W, Pichlmeier U, Meinel T, Wiestler OD, Zanella F and Reulen HJ; ALA-Glioma Study Group: Fluorescence-guided surgery with 5-aminolevulinic acid for resection of malignant glioma: A randomised controlled multicentre phase III trial. Lancet Oncol 7: 392-401, 2006.

24. Wood JR, Green SB and Shapiro WR: The prognostic importance of tumor size in malignant gliomas: A computed tomographic scan study by the brain tumor cooperative group. J Clin Oncol 6: 338-343, 1988.

25. Coffey RJ, Lunsford LD and Taylor FH: Survival after stereotactic biopsy of malignant gliomas. Neurosurgery 22: 465-473, 1988.

26. Duncan GG, Goodman GB, Ludgate CM and Rheaume DE: The treatment of adult supratentorial high grade astrocytomas. J Neurooncol 13: 63-72, 1992.

27. Quigley MR and Maroon JC: The relationship between survival and the extent of the resection in patients with supratentorial malignant gliomas. Neurosurgery 29: 385-388, 1991.

28. Barker CA, Chang M, Chou JF, Zhang Z, Beal K, Gutin PH and Iwamoto FM: Radiotherapy and concomitant temozolomide may improve survival of elderly patients with glioblastoma. J Neurooncol 109: 391-397, 2012

29. Ewelt C, Goeppert M, Rapp M, Steiger HJ, Stummer W and Sabel M: Glioblastoma multiforme of the elderly: The prognostic effect of resection on survival. J Neurooncol 103: 611-618, 2011

30. Iwamoto FM, Cooper AR, Reiner AS, Nayak L and Abrey LE: Glioblastoma in the elderly: The memorial sloan-kettering cancer center experience (1997-2007). Cancer 115: 3758-3766, 2009.

31. Chaichana KL, Chaichana KK, Olivi A, Weingart JD, Bennett R, Brem $\mathrm{H}$ and Quiñones-Hinojosa A: Surgical outcomes for older patients with glioblastoma multiforme: Preoperative factors associated with decreased survival. Clinical article. J Neurosurg 114: 587-594, 2011.

32. Oszvald A, Güresir E, Setzer M, Vatter H, Senft C, Seifert V and Franz K: Glioblastoma therapy in the elderly and the importance of the extent of resection regardless of age. J Neurosurg 116: 357-364, 2012.

33. Curran WJ Jr, Scott CB, Horton J, Nelson JS, Weinstein AS, Fischbach AJ, Chang CH, Rotman M, Asbell SO and Krisch RE: Recursive partitioning analysis of prognostic factors in three radiation therapy oncology group malignant glioma trials. J Natl Cancer Inst 85: 704-710, 1993. 
34. Intergroup Radiation Therapy Oncology Group Trial 9402; Cairncross G, Berkey B, Shaw E, Jenkins R, Scheithauer B, Brachman D, Buckner J, Fink K, Souhami L, Laperierre N, et al: Phase III trial of chemotherapy plus radiotherapy compared with radiotherapy alone for pure and mixed anaplastic oligodendroglioma: Intergroup radiation therapy oncology group trial 9402. J Clin Oncol 24: 2707-2714, 2006.
35. van den Bent MJ, Carpentier AF, Brandes AA, Sanson M, Taphoorn MJ, Bernsen HJ, Frenay M, Tijssen CC, Grisold W, Sipos L, et al: Adjuvant procarbazine, lomustine and vincristine improves progression-free survival but not overall survival in newly diagnosed anaplastic oligodendrogliomas and oligoastrocytomas: A randomized European organisation for research and treatment of cancer phase III trial. J Clin Oncol 24: 2715-2722, 2006. 